\title{
TIC en el Aula
}

Los beneficios y ventajas que las TIC produzcan en el aprendizaje escolar, ayudarán a los estudiantes a comprender y reflexionar sobre situaciones problemáticas, al margen de sus condiciones sociales o económicas, podrán facilitar a todos los alumnos al acceso a las fuentes del conocimiento sin considerar por ello que las TIC sean una tecnología absolutamente igualitaria en el aula.

\section{Las Tecnologías de la Información y la Comunicación (TIC).}

Las TIC están presentes en nuestra vida social más allá de considerar que es posible enseñar sin ordenadores en las escuelas. Históricamente los ordenadores se introdujeron sin haber pensado previamente las razones para hacerlo, es decir sin pensar en las metas educativas ni los beneficios potenciales de los mismos. Debemos ser conscientes de que la tecnología atrae a los estudiantes y hace que aprendan disfrutando; la PC tiene un poder motivador pero esto no significa que los estudiantes aprendan así algo importante, sino cómo aprenden y para qué.

\section{El Impacto de la Sociedad en Nuestro sistema Educativo.}

Esta sociedad del siglo XXI, impulsada por el avance científico en un marco socioeconómico neoliberal-globalizador sustentada por el uso de las tecnologías de la información y la comunicación (TIC), conlleva cambios en todos los ámbitos de la actividad del hombre, en especial en los ámbitos laborales y educativos. Este último remite a los cambios y adaptaciones respecto a la incorporación de las TIC como herramienta pedagógica.

Existen tres posibles reacciones de los centros docentes para adaptarse a las TICs y al nuevo contexto cultural, que son:

$\checkmark$ Escenario tecnócrata: donde las escuelas se adaptan realizando pequeños ajustes, a partir de la alfabetización digital.

$\checkmark$ Escenario reformista: donde se tienen en cuentan métodos de enseñanza-aprendizaje constructivistas que contemplan el uso de las TICs como instrumento cognitivo. TIC a través de actividades interdisciplinarias y colaborativas.

$\checkmark$ Escenario holístico: se llevan a cabo una reestructuración de todos sus elementos tecnológicos para abrirse al mundo.
Las instituciones

Educativas en el mundo tecnológico.

Los pilares de la educación (2003) hace notar la importancia de la dinámica de la sociedad de la información sobre el campo educativo, ya que crea un nuevo contexto en el que la educación afronta nuevos desafíos.

La tecnología permite abrir nuevos espacios para el saber y el conocimiento, el reto de los profesores no será impartir enseñanza, sino proporcionar las claves para poder encontrar la información más fidedigna, comprenderla y transmitirla adecuadamente.

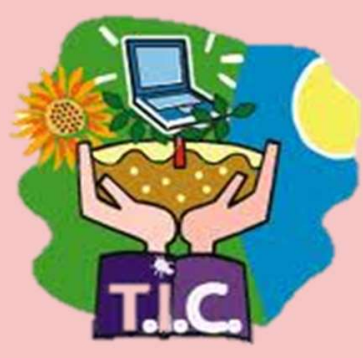

\section{Ing. Ruth Mujica}




\section{TIC en el Aula}

Una sociedad en Aprendizaje.

La revolución tecnológica abre a la enseñanza unos cauces inexplorados. Las tecnologías informáticas han duplicado las posibilidades de búsqueda de informaciones, y los equipos interactivos y multimedia ponen a disposición de los alumnos una cantidad inagotable de informaciones:

$\checkmark$ Ordenadores de todo tamaño y de variada complejidad.

$\checkmark$ Programas de televisión educativa por cable o satélite.

$\checkmark$ Sistemas interactivos de intercambio de información, incluidos el correo electrónico, y el acceso directo a las bibliotecas electrónicas y los bancos de datos.

$\checkmark$ Los simuladores electrónicos.

$\checkmark$ Los sistemas de realidad virtual en tres dimensiones.

Las redes telemáticas tendrían que orientarse en las siguientes direcciones:

$\checkmark$ Enseñar a buscar, para poder investigar y discernir lo trivial de lo importante en una oferta de información.

$\checkmark$ Enseñar a entender, captando la esencia de los conceptos y encontrando nuevas relaciones entre ellos.

$\checkmark$ Enseñar a aplicar el sentido crítico como norma en la construcción del conocimiento y en todas las conductas vitales.

$\checkmark$ Enseñar a comunicar y a expresar las propias ideas en un marco abierto al diálogo y al respeto mutuo.

\section{Las Grandes Aportaciones de las TIC}

De manera que con estos nuevos

instrumentos, los alumnos se convierten en investigadores. Los docentes enseñan a los alumnos a evaluar y a practicar la información que tienen a su disposición.

\section{Ing. Ruth Mujica}

\section{Los sistemas abiertos de aprendizajes:}

$\checkmark$ Estimulan el aprender a aprender, sustentado en el principio de actividad participativa aumentada por entornos virtuales y en el principio de responsabilidad en la formación de una comunidad de aprendizaje;

$\checkmark$ Orientan al estudiante en relación con el desempeño que se espera de él y lo conducen a participar en funciones, tareas, procesos y operaciones con grandes márgenes de autonomía;

$\checkmark$ Incluyen una máxima disponibilidad de información (rasgo, este último, que se ve propiciado por la presencia de TIC).

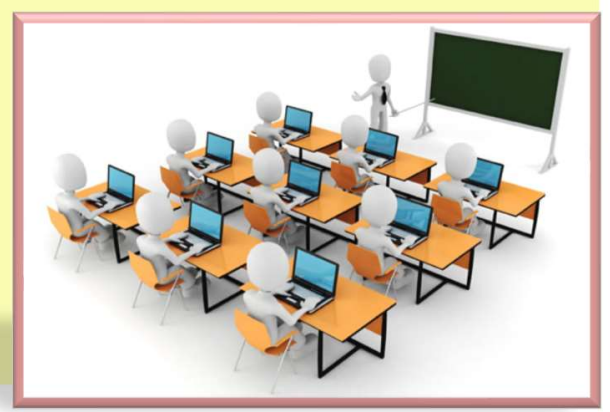

